\title{
Sosialisasi Pengembangan Kelompok Sadar Wisata Berbasis Sapta Pesona Di Desa Aranio Kecamatan Aranio Kabupaten Banjar Provinsi Kalimantan Selatan
}

\author{
Mahyuni ${ }^{1}$, Ismar Hamid ${ }^{2}$, Evanrio Seanjaya ${ }^{3}$, Muhammad Tifriji ${ }^{4}$, Muhammad Hatni ${ }^{5}$, Milda \\ Rahmawati $^{6}$, Widya Wati Rohmatul Jannah ${ }^{7}$, Norafifah ${ }^{8}$, Ahmad Rusadi ${ }^{9}$ \\ ${ }^{1}$ Program Studi Ilmu Pemerintahan, Universitas Lambung Mangkurat, Fakultas Ilmu Sosial dan Ilmu Politik, \\ Jl. H. Hassan Basry, Banjarmasin, Indonesia, \\ ${ }^{2}$ Program Studi Sosiologi, Universitas Lambung Mangkurat, Fakultas Ilmu Sosial dan Ilmu Politik, Jl. H. \\ Hassan Basry, Banjarmasin, Indonesia, \\ ${ }^{3,4,5,6,7}$ Mahasiswa Universitas Lambung Mangkurat, Fakultas Ilmu Sosial dan Ilmu Politik, \\ Jl. H. Hassan Basry, Banjarmasin, Indonesia \\ *email korespondensi : mahyuni.fisip@ulm.ac.id
}

Diajukan

29 Oktober 2021

\section{Informasi Artikel}

\author{
Diterima
}

20 November 2021
Diterbitkan

30 November 2021

\section{Keywords:}

Sosialisasi

7 Sapta Pesona

Desa Wisata

Pengbdian Masyarakat

\begin{abstract}
The tourism potential of the Flower River can be further developed if there is good management of structured tourism awareness groups under the supervision of the village government. In addition, the embodiment of Sapta Pesona (safe, orderly, clean, relaxed, beautiful, friendly, and memorable) in the Flower River creates a conducive and ideal environment for the development of tourism activities in a place. The purpose of the service is to increase public awareness to create an ideal Tourism Village based on 7 Sapta Pesona. The methodology used to develop the potential of this village is through the socialization of Awakening, the Sapta Pesona-Based Tourism Village, and the Development of Tourism Awareness Groups. From this activity, it will increase understanding of developing the tourism potential of Aranio Village, open up the insight of Flower River tourism managers so that they can plan programs that can rebuild Flower River tourism, the village government obtains the necessary reforms to revive tourist villages and can form legally aware tourism groups.
\end{abstract}

\begin{abstract}
ABSTRAK
Potensi wisata sungai kembang dapat lebih dikembangkan kembali apabila adanya pengelolaan yang baik dari kelompok sadar wisata yang terstruktur dibawah pengawasan pemerintah desa. Selain itu perwujudan sapta pesona (aman, tertib, bersih, sejuk, indah, ramah dan kenangan) di sungai kembang menciptakan lingkungan yang kondusif dan ideal bagi berkembangnya kegiatan kepariwisataan di suatu tempat. Tujuan pengabdian adalah untuk meningkatkan kesadaran masyarakat guna menciptakan Desa Wisata yang ideal berbasis 7 sapta pesona. Metode yang digunakan untuk mengembangkan potensi desa ini melalui sosialisasi Bangkitkan Desa Wisata Berbasis Sapta Pesona dan Pengembangan Kelompok Sadar Wisata.Dari kegiatan ini maka akan meningkatkan pemahaman tentang pengembangkan potensi wisata Desa Aranio, membuka wawasan pengelola wisata sungai kembang sehingga dapat merencanakan program yang dapat membangun kembali wisata sungai kembang, pemerintah desa memperoleh pembaharuan yang diperlukan untuk membangkitkan desa wisata serta dapat membentuk kelompok sadar wisata secara legal.
\end{abstract}

\section{Copyright and License:}

Authors retain copyright and grant the journal right of first publication with the work simultaneously licensed under a Creative Commons Attribution 4.0 International License that allows others to share the work with an acknowledgment of the work's authorship and initial publication in this journal. 


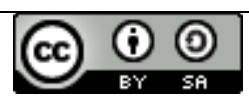

1. PENDAHULUAN

Desa wisata adalah aset kepariwisataan yang berbasis pada potensi pedesaan dengan segala keunikan dan daya tariknya yang dapat diberdayakan dan dikembangkan sebagai produk wisata untuk menarik kunjungan wisatawan ke wisata tersebut. Pewujudan desa wisata tidak terlepas dari peran masyarakat lokal sebagai tuan rumah yang memiliki peran penting dalam pengembangan desa wisata dalam keseluruhan tahapan mulai dari tahap perencanaan, pelaksanaan hingga implementasi (Sudibya, 2018).

Pariwisata merupakan industri yang bergerak dalam bidang pelayanan dan jasa yang menjadi andalan bangsa Indonesia untuk mendongkrak devisa Negara. Perkembangan pariwisata Indonesia yang sangat besar dan beragam dapat dikembangkan menjadi destinasi wisata yang menarik dan menjadi tujuan utama wisata dunia. Saat ini para wisatawan lebih menyukai wisata alam yang dikombinasi peran serta masyarakat dalam kebudayaan social kemasyarakatannya (Ridlwan, 2017).

Saat ini pariwisata menjadi sektor yang sangat menjanjikan dalam perkembangan global termasuk juga Indonesia.Seiring dengan perkembangannya muncul pariwisata berbasis masyarakat, yaitu pariwisata yang menyuguhkan segala sumber daya alami yang tidak hanya mengembangkan aspek lingkungan dalam hal konservasi saja, namun juga melibatkan kebudayaan dan social masyarakat sekitar sehinga memberikan keuntungan kepada masyarakat sekitar. Ekowisata diharapkan mampu mengembangkan perkonomian masyarakat sekitar dimana mereka adalah pengendali utama sector pariwisata tersebut (Tanaya, 2014).

Kelompok sadar wisata (Pokdarwis) merupakan bentuk realisasi dari peran masyarakat dalam pembentukan desa wisata. Pokdarwis berperan sebagai penggerak dalam mendukung terciptanya iklim yang kondusif dalam tumbuh dan berkembangnya kepariwisataan serta terwujudnya 7 sapta pesona dalam peningkatan pembangunan daerah melalui kepariwisataan dan memanfaatkanya untuk kesejahtaeraan masyarakat sekitar.

Desa Aranio yang terletak di Kecamatan Aranio Kabupaten Banjar Provinsi Kalimantan Selatan memiliki potensi wisata yang cukup menarik yaitu Sungai Kembang. Sungai Kembang merupakan wisata berupa arus air yang sangat asri karna kondisi lingkungannya yang masih terjaga. Sungai Kembang menyajikan panoramaalam yang sangat indah dengan iringan derasnya arus air yang melewati bebatuan di sungai memiliki daya tarik tersendiri untuk dinikmati. Potensi wisata Sungai Kembang sudah cukup baik.

Untuk menarik wisatawan, akan tetapi tidak terstrukturnya pengelola wisata di Desa Aranio yang diakibatkan dari kekosongan jabatan pembakal desa selama dua tahun terakhir menjadikan destinasi wisata ini tidak beroperasi dengan baik. Kurang tahunya masyarakat luas akan adanya destinasi wisata sungai kembang juga menjadi suatu masalah minimnya pengunjung yang datang.

Potensi wisata sungai kembang dapat lebih dikembangkan kembali apabila adanya pengelolaan yang baik dari kelompok sadar wisata yang terstruktur dibawah pengawasan pemerintah desa. Selain itu perwujudan sapta pesona (aman, tertib, bersih, sejuk, indah, ramah dan kenangan) di sungai kembang menciptakan lingkungan yang kondusif dan ideal bagi berkembangnya kegiatan kepariwisataan di suatu tempat yang mendorong tumbuhnya minat wisatawan untuk berkunjung (kreatif, 2012).

Pengabdian masyarakat melalui Kuliah Kerja Nyata (KKN) FISIP Universitas Lambung Mangkurat 2021 menjadi media implementasi ilmu pengetahuan dan teknologi yang dilaksanakan dalam jangka waktu dan prosedur tertentu yang dilaksanakan secara langsung. Kegiatan ini berbasis pada luaran berupa penguatan pengetahuan, dan keterampilan masyarakat atas berbagai inovasi baru sesuai dengan karakter lokal yang ada. KKN di Desa Aranio bertujuan untuk meningkatkan potensi yang ada di Desa Aranio melalui program sosialisasi sadar wisata. Dengan di jalankannya program tersebut diharapkan dapat mengembangkan potensi wisata Desa Aranio, membuka wawasan pengelola wisata sungai kembang sehingga dapat merencanakan program yang dapat membangun kembali wisata sungai kembang, pemerintah desa memperoleh pembaharuan yang diperlukan untuk membangkitkan desa wisata serta dapat membentuk kelompok sadar wisata secara legal dan terstruktur.

Berdasarkan latar belakang diatas maka diperlukan suatu upaya yang masif untuk dapat membangkitkan kembali kelompok sadar wisata di Desa Aranio sebagai langkah utama untuk menghidupkan kembali wisata sungai kembang menjadi destinasi wisata dengan pengelolaan yang terstruktur dan sistematis yang berlandaskan pada sapta pesona. Melihat hal tersebut maka diperlukan pengabdian masyarakat dengan judul "Sosialisasi Pengembangan Kelompok Sadar Wisata Berbasis Sapta Pesona di Desa Aranio Kecamatan Aranio Kabupaten Banjar Provinsi Kalimantan Selatan”. 


\section{METODE}

Metode yang digunakan dalam Pengabdian Kepada Masyarakat (PKM) ini menggunakan metode analisis deskriptif dengan pendekatan kualitatif. Menurut Sugiyono (2017:59), metode deskriptif adalah penelitian yang melukiskan, mengambarkan, atau memaparkan keadaan objek yang diteliti sebagai apa adanya, sesuai dengan situasi dan kondisi ketika penelitan tersebut dilakukan, Penelitian ini juga menggunakan pendekatan kualitatif. Menurut Saryono (2010), Penelitian kualitatif adalah penelitian yang digunakan untuk menyelidiki, menemukan, menggambarkan, dan menjelaskan kualitas atau keistimewaan dari pengaruh sosial yang tidak dapat dijelaskan, diukur atau digambarkan melalui pendekatan kuantitatif. Pelaksanaan pemberdayaan masyarakat di lakukan di Desa Aranio, Kecamatan Aranio, Kecamatan Banjar.

Sosialisasi adalah sebuah proses belajar seumur hidup di mana seorang individu mempelajari kebiasaan dan kultur masyarakat yang meliputi cara hidup, nilai- nilai, dan norma-norma sosial yang terdapat dalam masyarakat agar dapat diterima dan berpartisipasi aktif di dalamnya. Dalam arti sempit, sosialisasi merupakan proses memperkenalkan sebuah sistem pada seseorang dan bagaimana orang tersebut menentukan tanggapan serta reaksinya. Tahapan yang digunakan dalam program untuk menumbuhkan rasa cinta terhadap wisata yang ada yaitu dengan Sosialisasi, dengan judul "Bangkitkan Desa Wisata Berbasis 7 Sapta Pesona \& Pengembangan Kelompok Sadar Wisata", Dalam sosialisasi kami memberikan pemaparan dan buku panduan peserta berupa buku pedoman sadar wisata. Tahapan selanjutnya yaitu memberikan pemaparan tentang pentingnya memasarkan wisata yang ada di desa agar masyarakat luar dapat mengenal wisata yang ada di desa, dengan memanfaatkan media sosial. Selain itu Karena penunjuk wisata di sana tidak layak maka juga di laksanakan pemasangan banner pariwisata sungai kembang yang ada di desa Aranio, Kecamatan Aranio, Kabupaten Banjar, Kalimantan Selatan.

\section{HASILDANPEMBAHASAN}

Pengembangan Desa Wisata Melalui Sosialisasi Pembentukan Kelompok Sadar Pariwisata (POKDARWIS) di Desa Aranio, Kecamatan Aranio, Kabupaten Banjar dilaksanakan secara bertahap melalui beberapa proses yang melibatkan pengelola wisata dan pemerintah desa. Selain mewujudkan desa wisata yang berlandaskan pada Sapta Pesona, pada kegiatan sosialisasi ini juga diharapkan tumbuhnya kesadaran masyarakat akan pariwisata yang baik guna meningkatkan kualitas potensi wisata yang ada. Untuk mendukung hal tersebut, dalam kesempatan ini akan diberikan pula buku pedoman POKDARWIS sebagai pendamping pembentukan Kelompok Sadar Wisata (Pokdarwis) di Desa Aranio dengan harapan Kelompok Sadar Wisata ini dapat menjadi teladan bagi masyarakat sebagai penerima manfaat yang sebesar-besarnya dari adanya pengembangan kegiatan kepariwisataan.

Adpun Tahapan yang dilakukan pada kegiatan sosialisasi pengembangan desa wisata sebagai berikut:

\section{Tahapan persiapan}

Tahapan persiapan dilakukan koordinasi dan komunikasi dengan Aparatur Desa , Pengelola wisata dan masyarakat Desa Aranio untuk memberikan penjelasan pengembangan Desa Wisata yang akan kembali dirintis oleh Desa Aranio dan untuk menimbulkankan segmentasi agar masyarakat Desa Aranio khususnya yang memiliki kesadaran akan parawisata tempat.

Lokasi pengembangan desa wisata dalam pengabdian kepada masyarakat terletak di Desa Aranio Kecamatan Aranio Kabupaten Banjar. Wisata Desa Aranio dahulunya pernah terkelola dengan baik, diantaranya wisata sungai kembang dan bukit arta, tetapi wisata sungai kembang tersebut terbengkalai akibat pengelola kurang maksimal dalam mengelola wisata tersebut sedangkan wisata Bukit Arta mengalami penutupan total dikarenakan jembatan penyebrangan yang biasanya dilalui ke wisata tersebut putus dikarenakan banjir yang terjadi pada beberapa bulan lalu.

Tahapan persiapan berikutnya dilakukan peninjauan dan survei dalam penentuan pengembangan Desa Wisata. Klasifikasi Pengembangan Desa Wisata rintisan dalam Panduan Desa Wisata dengan menggunakan kriteria sebagai berikut (2021:46):

a. Masih berupa potensi yang dapat dikembangkan untuk menjadi destinasi wisata.

b. Pengembangan sarana prasana wisata masih terbatas.

c. Belum ada/masih sedikit sekali wisatawan berkunjung dan berasal dari masyarakat sekitar.

d. Kesadaran masyarakat terhadap potensi wisata belum tumbuh.

e. Sangat diperlukan pendampingan dari pihak terkait (pemerintah, swasta). 
f. Memanfaatkan Dana Desa untuk pengembangan Desa Wisata.

g. Pengelolaan desa wisata masih bersifat lokal desa.

\section{Tahapan pelaksanaan sosialisasi}

Melihat hasil dari peninjauan akses sarana dan prasarana serta wisata yang ingin dikembangkan oleh Desa Paring Tali diperlukan edukasi untuk meningkatkan peran masyarakat dalam pembangunan Desa Wisata yang memerlukan berbagai upaya pemberdayaan (empowerment), agar masyarakat dapat berperan lebih aktif dan optimal serta sekaligus menerima manfaat positif dari kegiatan pembangunan yang mensejahterakan masyarakat melalui Desa Wisata. Pelaksanaan Sosialisasi dilakukan dengan memberikan penyuluhan tentang sadar wisata kepada aparatur desa dan pengelola desa untuk meningkatkan kesadaran masyarakat guna menciptakan desa wisata yang ideal berbasis 7 sapta pesona dalam bentuk sosialisasi dan pemberian buku Panduan Kelompok Sadar Wisata (POKDARWIS).

Konsep pelaksanaan:

- Penjelasan menganai kriteria yang harus dipenuhi dalam penetapan desa wisata yang ideal.

- Sadar Wisata dan tujuan mengenai konsep Sadar Wisata.

- Penjelasan mengenai Tujuh Sapta Pesona dan bentuk aksi yang dapat diwujudkan.

- Langkah-langkah membentuk Kelompok Sadar Wisata.

Kegiatan ini dilaksakan di aula desa dan bertujuan untuk:

- Meningkatkan kesadaran, peran, dan tanggung jawab masyarakat terhadap lingkungan wisata yang ada di Desa Aranio.

- Menyadari hak dan kebutuhannya untuk menjadi pelaku wisata atau wisatawan untuk melakukan perjalanan ke suatu daerah tujuan wisata.

- Mewujudkan wisata yang berlandaskan 7 sapta pesona (aman, tertib, bersih, sejuk, indah, ramah, dan kenangan).

\section{Ketercapaian sasaran}

Setelah pelaksanaan kegiatan pengabdian yakni berupa sosialisasi dan pelatihan branding desa wisata maka berikut ini ketercapaian sasaran kegiatan:

1. Pemerintah desa dan pengelola memahami pentingnya pengembangan desa wisata melalui Pembentukan Kelompok Sadar Wisata (POKDARWIS).

2. Pemerintah Desa dan pengelola memahami tata cara branding desa wisata.

3. Pemerintah Desa mengaplikasikan branding desa wisata melalui pemasangan Benner dan pembuatan videography desa.

4. Tumbuhnya motivasi masyarakat untuk melakukan branding wisata Sungai Kembang dan Bukit Arta.

\section{Kesimpulan}

1. Pariwisata merupakan industri yang bergerak dalam bidang pelayanan dan jasa yang menjadi andalan bangsa Indonesia untuk mendongkrak devisa Negara. Perkembangan pariwisata Indonesia yang sangat besar dan beragam dapat dikembangkan menjadi destinasi wisata yang menarik dan menjadi tujuan utama wisata dunia. Desa aranio memiliki potensi wisata yang menarik yaitu sungai kembang, namun tidak terstrukturnya pengelola wisata di desa aranio yang diakibatkan oleh kekosongan jabatan pembakal desa selama 2 tahun terakhir mengakibatkan destinasi wisata ini tidak beroperasi dengan baik. Potensi wisata sungai kembang dapat lebih dikembangkan kembali apabila adanya pengelolaan yang baik dari kelompok sadar wisata yang terstruktur dibawah pengawasan pemerintah desa.

2. Setelah melakukan komunikasi dan koordinasi dengan aparatur desa,pengelola wisata dan masyarakat desa tentang kelompok sadar wisata (pokdarwis) diharapkan membangun kesadaran akan potensi wisata di desa tersebut.

3. Melakukan pelatihan branding desa seperti pembuatan banner atau videography desa bertujuan untuk mengenalkan desa aranio mempunyai destinasi wisata indah. 


\section{UCAPAN TERIMA KASIH}

Ucapan terima kasih disampaikan kepada FISIP Universitas Lambung Mangkurat yang telah mendukung berlangsungnya kegiatan ini.

\section{REFERENSI}

Kementrian Pariwisata dan Ekonomi Kreatif. 2012. Pedoman Kelompok Sadar Wisata. Jakarta: Kementrian Pariwisata dan Ekonomi Kreatif.

Kementrian Pariwisata dan Ekonomi Kreatif. 2021. Pedoman Desa Wisata.

Ridlwan, M.A., Muchsin, S. Hayat. 2017. Model Pengembangan Ekowisata dalam Upaya Pemberdayaan Masyarakat Lokal. Indonesian Political Science Review 2 (2) 141-158.

Saryono. 2020. “Pendekatan Kualitatif “ https://raharja.ac.id/2020/10/29/penelitian-kualitatif/ , diakses pada 17 september 2021 Pukul 09.37

Sudibya, Bagus. (2018). Wisata Desa dan Desa Wisata. Jurnal Bappeda Litbang, Vol. 1, No. 1, Halaman 22-23. Sugiyono. 2020. "Metode Deskriptif Kualitatif"

https://repository.usm.ac.id/files/skripsi/B11A/2015/B.111.15.0308/B.111.15.0308-06-BAB-III20200323090004.pdf, diakses pada 17 September 2021 Pukul 08.13

Tanaya, D.R. 2014. Potensi Pengembangan Ekowisata Berbasis Masyarakat di Daerah Rawa Pening, Kabupaten Semarang. Jurnal Teknik PWK 3(1) 71-81

https://www.merdeka.com/sumut/tujuan-sosialisasi-jenis-pengertian-menurut-para-ahli-dan-medianya-kln.html 